Área Abierta. Revista de comunicación

audiovisual y publicitaria

ISSN: 2530-7592 / ISSNe: 1578-8293

\title{
El audiovisual como herramienta para el reconocimiento de la identidad artística: el caso de María Mallo
}

\author{
Marcelo Fraile Narvaez ${ }^{1}$
}

Recibido: 13 de diciembre de 2021 / Aceptado: 18 de enero de 2022

Resumen. Conceptualmente, el arte desarrolla de manera continua obras a través de diferentes lenguajes, los cuales siempre se están renovando. Quizás algunos de los elementos que más han influido en este proceso de cambio sean el de los sistemas digitales, herramientas que nos han revelado una perspectiva diferente. Un ejemplo interesante al respecto es el de la artista española María Mallo: en sus obras toma diferentes referencias, que van desde las estructuras de los esqueletos radiolarios hasta patrones geométricos naturales, para producir una realidad creada que puede ser conocida y reconocida a través de la tecnología. A partir de estos conceptos, este trabajo tiene como objetivo utilizar los vídeos producidos por Mallo entre 2015 y 2021 como una herramienta de investigación documental, que permita conocer los procesos de desarrollo y creación utilizados en su producción artística. Un proceso que parece superponer los límites de la imaginación, buscando redefinir los conceptos tradicionales de arte.

Palabras clave: María Mallo; audiovisual; instalación; arte biodigital; arte biológico

\section{[en] Audiovisual as a Tool for the Recognition of Artistic Identity: The Case of María Mallo}

\begin{abstract}
Conceptually, art continually develops works through different languages, which are always being renewed. Perhaps some of the elements that have most influenced this process of change are digital systems, tools that have revealed a different perspective. An interesting example in this regard is that of the Spanish artist María Mallo: in her works, she takes different references ranging from the structures of radiolarian skeletons to natural geometric patterns, to produce a created reality which can be known and recognized through technology. From these concepts, this work aims to use the videos produced by Mallo between 2015 and 2021 as a documentary research tool, which allows to know the processes of development and creation used in her artistic production. A process that seems to superimpose the limits of imagination, seeking to redefine the traditional concepts of art.
\end{abstract}

Keywords: María Mallo; audiovisual; installation; biodigital art; biological art

Sumario. 1. Introducción. 2. Dos lados del cerebro. 3. El vídeo como herramienta para conocer las obras de María Mallo. 4. El proceso creativo: entre el ensayo y el error. 5. Tecnología + Arte: la construcción de formas que reproducen a la naturaleza. 6. La temporalidad de la obra de arte: el carácter de lo efímero. 7. Conclusiones: un manifiesto en fragmentos. 8. Bibliografía.

1 Universidad Internacional de La Rioja (España).

E-mail: marcelo.fraile@unir.net

ORCID: https://orcid.org/0000-0002-9321-4512 
Cómo citar: Fraile Narvaez, M. (2022). El audiovisual como herramienta para el reconocimiento de la identidad artística: el caso de María Mallo. Área Abierta. Revista de comunicación audiovisual y publicitaria 22 (1), 79-93, https://dx.doi.org/10.5209/arab.79314

\section{Introducción}

Para la profesora Marta Zátonyi (2011a), el arte en su relación con la vida del hombre, con su gran capacidad de crear, continuamente desarrolla obras a través de diferentes lenguajes, los cuales siempre se están renovando. De igual modo, "pensaremos el arte como un objeto de goce y estudio cuya aprehensión está balanceada entre sentir, percibir y saber" (Zátonyi, 2011a: 17). Sus pares forman una suma dinámica encadenada por una constante interacción con el medio, para formar una red compleja, un entretejido sensible. En este sentido, la llegada y desarrollo de los sistemas digitales de bajo presupuesto han permitido la producción y postproducción de piezas audiovisuales con cierta facilidad, generando un efecto de aceleración en los procesos creativos que trasciende la inmediatez de lo próximo para acceder a la de lo lejano, lo distal. En el proceso, se ha modificado la cultura y la relación entre los individuos (Zátonyi, 2011b).

Quizás algunos de los elementos que más han influido en este proceso de cambio sean el de los sistemas digitales, las redes sociales y los espacios en red: herramientas de apertura que nos han revelado un nuevo panorama, con una perspectiva diferente; un mundo de comunicación permanente, que nos obliga a estar conectados los 365 días del año. Una cultura audiovisual que favorece la comunicación sensorial-racional ante un medio ampliamente utilizado, cuya característica principal es su espíritu de cambio.

En el campo específico del arte, la tecnología audiovisual en red ha permitido conocer y acercar un mundo que hasta hace poco podría parecernos local, transformando a sus creadores en artistas globales, que influyen y son influenciados por una cultura multidisciplinar de carácter mundial, un espacio donde diferentes culturas, estéticas y lenguajes se entremezclan a veces sin poder definir sus límites con precisión. En el camino, la tecnología en general, y la aparición de nuevas herramientas digitales accesibles sin conocimientos complejos en particular, ha dotado a los artistas de nuevos instrumentos de creación, que les posibilita explorar un desconocido campo de acción donde la tecnología, la técnica, el arte, la biología y el diseño se amalgaman en sus creaciones disruptivas. Se trata de un combate permanente entre lo dogmático y lo espontáneo, una pelea encarnizada donde las vanguardias se enfrentan a todo aquello que pretende suprimir y restringir la libertad creativa, un proceso de experimentación cuyo hacer tensa las fronteras de la expresividad.

Un ejemplo interesante al respecto lo podemos encontrar en las creaciones de la artista-arquitecta española María Mallo: en sus investigaciones toma diferentes referencias, que van desde las estructuras de los esqueletos radiolarios hasta patrones geométricos naturales. Se trata de un proceso que busca encontrar en las formas biológicas estudiadas una lógica de eficiencia, pero también su belleza inherente definida en su simpleza. Un proceso de investigación por recuperar un equilibrio inestable entre lo abstracto y lo empírico, lo racional y lo intuitivo, lo artificial y lo natural, dando lugar a confrontaciones dialécticas en constante evolución. En su arte, Mallo produce una realidad creada, que puede ser conocida y reconocida a través de la tecnología; a través de una serie de vídeos de carácter amateur producidos por la autora y compartidos en línea o mediante las redes sociales, Mallo parece querer establecer un acercamiento temporal a su proceso creativo. 
Un proceso que busca comprender las sensaciones que sugieren lo imposible del espacio ilimitado, una realidad sin fronteras, una realidad cultural, natural y tecnológica: en sus obras "el arte se integra en la propia entraña del misterio de la creación haciendo, a su vez, accesible el enigma a través del signo" (Zátonyi, 2011a: 49).

Bajo una propuesta eminentemente práctica, sus vídeos se transforman en huellas, pisadas en la arena donde, entre líneas, se revela el carácter del artista, una relación entre el arte, el diseño y la tecnología que se funden hasta desaparecer como unidades inherentes de ser reconocidas.

A partir de estos conceptos, este trabajo tiene como objetivo utilizar los vídeos producidos por María Mallo - entre 2015 y 2021 y compartidos en la web- como una herramienta de investigación documental, que permita conocer los procesos de desarrollo y creación utilizados en sus obras. Un proceso de construcción y configuración que pretende delinear los esbozos de una cartografía más extensa, que nos acerque a la configuración de un mapa de relaciones usado por Mallo para sus creaciones artísticas, un proceso que, a priori, parece superponer los límites de la imaginación, buscando reagrupar y redefinir los conceptos tradicionales de arte-Imagen 1-. Un arte accesible no a todos, que requiere de un código especial para percibirlo, para entenderlo, para descifrarlo; los afortunados poseedores de ese código jugarán un papel sustancial en el efecto que este arte provoca en el espectador.

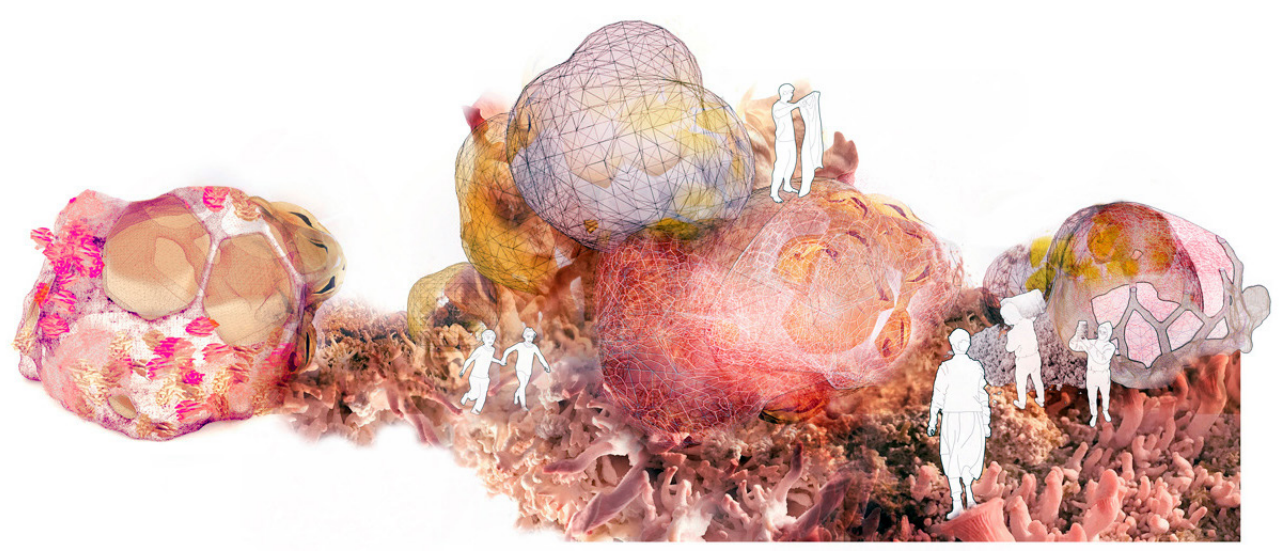

Imagen 1. Breeding Space. Se trata de "una arquitectura que está viva, crece, se cultiva e incluso genera subproductos comestibles. Un espacio criado a partir de algoritmos generativos y micelio de seta de ostra sobre paja". [Fuente: https://mariamallo.com/Breeding-Space]

\section{Dos lados del cerebro}

Diseñadora y creadora multidisciplinar, María Mallo, se licenciaría en Arquitectura en 2006. Posteriormente comenzaría sus estudios de doctorado, del que egresaría en 2015, no sin grandes problemas para encontrar un director que aceptara su tema por considerarse que no era una tesis relacionada con el campo de la arquitectura.

De forma paralela al doctorado, entre 2007 y 2010, Mallo estudiaría Artes Plásticas y Escultura, aprendiendo técnicas de modelado, moldes, talla en madera y pie- 
dra, forja y soldadura. Una búsqueda creativa, en un afán por descubrir lo extraño y novedoso. Durante un largo tiempo, Mallo se creyó el patito feo del mundo de la arquitectura al diseñar proyectos considerados por sus profesores como "no arquitectura", edificios que no eran "normales"2: sus obras parecen estar dominadas por un impulso primigenio que la lleva a realizar lo que a ella le gusta llamar "las cosas más extrañas". Un concepto que vagamente nos recuerda aquel pensamiento hegeliano, según el cual lo feo es el demonio y su lugar esta fuera del arte (Zátonyi, 2011b: 88). Pero en Mallo esa "monstruosidad", ese "demonio", queda recompensado al rebasar los límites normales, para convertirlo en un valle de tierras fértiles que le permite producir nuevas creaciones estilísticas, que ponen en crisis el viejo orden definido por el paradigma existente.

Tras un largo proceso de búsqueda, ha logrado reconciliar las dos partes de su cerebro, dos mundos aparentemente enfrentados: por un lado, el expresivo o artístico, y por el otro, el científico, el relacionado con la técnica y la rigurosidad de la naturaleza hilemórfica: "lo orgánico contra lo regular, las emociones contra el razonamiento" (Mallo, 2017). Un proceso de reconciliación que pudo ser posible gracias al estudio de las geometrías complejas de la naturaleza, al descubrir que, en sus creaciones, la naturaleza vincula la belleza y complejidad de la forma, pero también la eficiencia en el desarrollo de los procesos ${ }^{3}$.

En sus investigaciones, Mallo se ha centrado en el crecimiento de patrones irregulares, basados en sistemas autoorganizados que dependen de principios de tensión superficial y empaquetamiento óptimo. Una investigación morfológica que ha desbordado los límites disciplinares en sus múltiples escalas: desde la joyería, a la escultura y la arquitectura.

Gracias al uso de la tecnología y de los algoritmos generativos, Mallo ha podido construir a mayores niveles de complejidad sin perder la validez estética de sus obras: una fusión entre el hacer de la naturaleza, con el replicar mediante ecuaciones matemáticas de la técnica. Una combinación entre las formas de la naturaleza, el diseño paramétrico y las nuevas tecnologías de prefabricación, con el fin de reproducir los comportamientos de la biología. Para María Mallo, se trata de un mundo totalmente inagotable, donde patrones y series de comportamiento se vinculan con diferentes materiales y procesos de fabricación.

Desde un capullo colgante hasta la cabina suspendida de un hotel en un acantilado o la esfera geodésica con un feto en su interior, sus obras presentan un proceso continuo de reinterpretación de las formas naturales: “... cuerpos que flotan y que se mueven por pequeños y suaves mundos, todos diferentes y todos conectados" (Mallo, 2017). Una mezcla heterogénea de materiales, técnicas y procesos donde alternan el papel cortado con láser, tubos de PVC, joyas experimentales de silicona, cañas de ratán y objetos de porcelana. Son espacios líquidos de paredes onduladas, suelos complejos y techos continuos, que reaccionan a las necesidades de los seres humanos, un espacio donde es imposible distinguir que es natural y que artificial. Sus proyectos han sido expuestos en prestigiosos lugares como la Biennale de Rabat 2019; la Central de Diseño de Madrid; el space to be de Madrid; la Bienal Ludantia 2018; la Biennale d'Architecture d'Orléans 2017; el MediaLab Prado; Matadero

2 En una vídeo-entrevista realizada a finales de 2020 por el autor, Mallo revela lo complejo de su camino transitado entre arquitectura y arte.

3 Vídeo entrevista (Mallo, 2021). 
Madrid; el COAM; la Sala de Arte Joven de la Comunidad de Madrid y la Casa de la Cultura de El Escorial, entre otros.

\section{El vídeo como herramienta para conocer las obras de María Mallo}

Con el desarrollo y la difusión de los sistemas digitales, en especial de las cámaras fotográficas, filmadoras y teléfonos inteligentes, la producción de piezas audiovisuales se ha generalizado a un público cada vez más extendido. Una nueva familia de dispositivos, de fácil uso y de gran diversidad de formatos, han hecho accesible la producción y posproducción de vídeos y diseños multimediales a un público no especializado en el tema.

En este sentido, el vídeo se ha convertido en un elemento que facilita el recuerdo y la comprensión de la información; una multitud de tutoriales y piezas audiovisuales son testigos de este procedimiento de registro. Sin embargo, también el vídeo se ha convertido en un recurso utilizado como un elemento simbólico con amplias posibilidades narrativas, facilitando la construcción de un conocimiento significativo y con la suficiente capacidad como para transmitir una serie de experiencias que estimulen a los sentidos. En los últimos tiempos, y gracias a la proliferación de diferentes plataformas en red, los medios audiovisuales se han transformado no solo en meros transmisores de información, sino que se han convertido en elemento de expresión, buscando abrir interrogantes, suscitar problemas o despertar el interés. Un factor que, en el caso particular de la obra de Mallo, ha jugado un papel fundamental, al transformarse en fuente documental primaria de su producción artística a través del tiempo. Un recurso audiovisual abundante, aunque muchas veces enmarañado y disperso, pero con el suficiente poder como para permitirnos reconstruir sus procesos creativos, sus principios estéticos y sus obras más icónicas.

A los fines prácticos de este trabajo, y con la intención de identificar los rasgos principales de la obra de Mallo, hemos establecido tres categorías: 1) El proceso creativo: entre el ensayo y el error; 2) Tecnología + Arte: la construcción de formas que reproducen a la naturaleza; y 3 ) La temporalidad de la obra de arte: el carácter de lo efímero

\section{El proceso creativo: entre el ensayo y el error}

Como antes vimos, con la proliferación y difusión de las plataformas audiovisuales en red, el vídeo se ha convertido en una herramienta de investigación, un sistema que permite indagar y recoger la información, pudiendo reconstruir realidades; un elemento activo que permite documentar los procesos, las situaciones, los rituales, observar y comprender actividades creativas, así como obtener la información de las técnicas utilizadas. En este sentido, al usar los vídeos producidos por María Mallo como una herramienta estructural narrativa, es posible definir los sustentos metodológicos que permiten registrar una dinámica creativa singular, un fenómeno experimental que, en su desarrollo, es capaz de expresar anomalías, expresiones singulares de un arte biológico materializado a través de herramientas digitales.

Un vídeo interesante al respecto es PII-01: una estructura ramificada de sombras del proyecto del mismo nombre. Un proyecto desarrollado junto con estudiantes del 
Máster de la Escuela de Arquitectura de Madrid, entre febrero y julio de 2021. A través de un vídeo de elaboración amateur, es posible conocer el proceso de construcción de una estructura espacial artística empleada para dar sombra al patio de una casa familiar. El proyecto es un proceso cuyo estudio y aprehensión se encuentra balanceado entre el sentir, el percibir y, por supuesto, el saber. A través del vídeo, es posible precisar las diferentes etapas seguidas por la artista en la construcción de una forma escultural tridimensional.

Inicialmente, la artista comienza su proceso de búsqueda y experimentación a través del trazado y elaboración de bocetos a mano alzada: ideas apriorísticas que intentarán descifrar y descubrir la idea primigenia de la obra. En sus trazos, se descubre un proceso que busca imitar los modelos formales de la naturaleza; a través de un camino propio intenta elaborar formas sinuosas, estructuras irregulares que rompen la simetría y el orden de una geometría homeomorfa. Mediante un proceso impulsado por el "aprender haciendo", Mallo desarrolla un autoaprendizaje, fomentando la transversalidad, la libertad creativa y los procesos exploratorios. En esencia, estamos ante una ruptura de las reglas prefijadas por la academia, destruyendo y reconstruyendo la obra de arte bajo un proceso de resignificación, un proceso marcado por el espacio y por el tiempo. Un camino que vincula el mundo del diseño con el mundo del arte, de la tecnología y de la biología, con el fin de crear nuevas obras con un lenguaje único.

A continuación, los bocetos, los borradores físicos son digitalizados mediante la utilización de programas y algoritmos paramétricos digitales: un proceso que transforma lo análogo en binario buscando dar precisión a la forma. Pero esta transformación no es lineal, ni literal; por el contrario, se trata de un proceso de experimentación constante. Un sistema que sacude las pautas tradicionales del arte para elaborar las suyas: ni positivas, ni negativas, su esencia plantea lo irrepetible a través de su proceso aleatorio, que acepta las mutaciones, como símbolos, "posibilitando soportar lo insoportable y aprovechar la fugacidad, en lugar de rechazarla" (Zátonyi, 2011b: 193-194). Como si de un proceso circular se tratase, los modelos digitales son transformados en modelos tridimensionales conceptuales y viceversa: maquetas físicas de experimentación, que a su vez modifican y alteran el modelo digital; un ida y vuelta que busca ajustar el modelo a su condición óptima, como si de una pieza de relojería se tratase.

La siguiente fase transcurre en el taller. Bajo un proceso de prueba y error, comienza una etapa itinerante en donde Mallo analiza el desarrollo de los procesos, seleccionando las acciones y tecnologías más adecuadas para llevar a cabo la materialización de la obra: desde el micelio, la kombucha o el bioplástico, Mallo desarrolla un proceso de investigación que la lleva a utilizar materiales naturales, buscando una coherencia entre las formas usadas y los procesos constructivos empleados. Se trata de un proceso temporal fragmentado, una estrategia práctica planteada a través del ajustar "mientras se hace". Desde este enfoque, la sorpresa, la búsqueda de lo exótico o lo curioso, le permite establecer un nuevo proceso narrativo, un estilo desestructurado, donde a través de la materialidad busca construir su propia mirada, su propio relato.

Ajustado el proceso constructivo, así como los diferentes materiales a emplear, comienza la etapa de construcción de la obra, que en el caso de instalaciones como la PII-01, significaban desplazarse hasta el sitio (Valsaín), junto con materiales, equipos y grupo de trabajo. Conceptualmente, se trata de un proceso de montaje y 
construcción in situ. Una etapa donde Mallo aprovecha para continuar el proceso de experimentación colaborativa hasta su materialización definitiva. De acuerdo con el planteo inicial, el resultado será siempre diferente: formas de amebas, estructuras teseladas o formas que se estrujan y comprimen. Un proceso de mutación semejante a los existentes en la naturaleza, donde la obra parece evolucionar con el paso del tiempo: algo que queda bien reflejado en el vídeo PII-01, en donde se plantea un cambio en la idea primigenia "cuando se coloca una malla de gallinero con esparto para dar sombra durante el verano", y con la llegada del otoño, "se retira el esparto para evitar la acumulación de nieve y se plantan enredaderas", montando una estructura de fibra óptica y nebulizadores dándole un carácter estético particular (Mallo, 2021). Por último, el proceso parece concluir con el registro y la publicación en línea de la pieza audiovisual, un documento digital sobre la evolución de la obra -Imagen 2-.

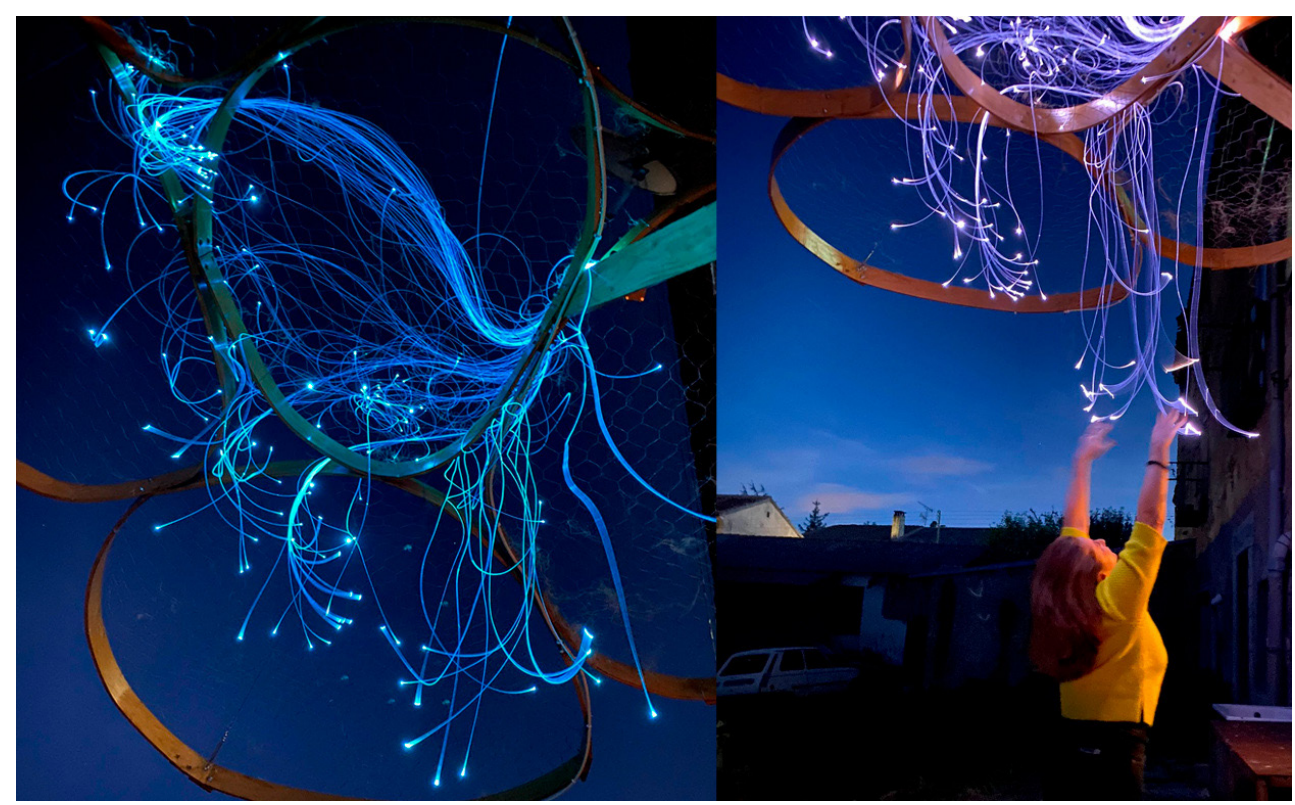

Imagen 2. PII-01. Con la llegada del otoño, retiraron el esparto para evitar la acumulación de nieve y montaron una estructura de fibra óptica y nebulizadores, dándole un carácter estético particular. [Fuente: https://mariamallo.com/PII-01]

\section{Tecnología + Arte: la construcción de formas que reproducen a la naturaleza}

Gracias al uso de las nuevas tecnologías digitales, Mallo pudo acceder a la materialización de sus creaciones, un proceso de experimentación mediante formas colaborativas y el uso de la fabricación digital, cuya inspiración es la propia naturaleza. En lo biológico, Mallo parece buscar inspiración, pero también reconciliación, una conexión compleja que rebasa cualquier regla preestablecida. Un proceso que busca elaborar un fenómeno, mientras se experimenta. Una ruptura de la obviedad que amenaza lo elemental, lo regular, lo normativo. 
A través de una serie de vídeos, se identifica la fuerte impronta tecnológica en la obra de Mallo: una producción audiovisual que busca hacer preguntas ahí donde no hay respuestas únicas; preguntas donde es imposible la solución aparente, ni siquiera las promete; va construyendo la circunstancia para indagar, no para resolver (Zátonyi, 2011b: 174). Se trata de una renovación, un suceso que sugiere y provoca una diversidad de fuerzas, un cambio sobre la realidad presente. Una ruptura del paradigma mecanicista, donde la otredad, el asombro y la ambigüedad logran incitar una nueva mirada. Un proceso que altera la realidad para penetrar en un espacio subjetivo, algo que subyace en lo más recóndito de nuestra vida.

Un ejemplo interesante al respecto es la instalación Ecosistemas emocionales diversos, del 2017, incluida en la exposición "En los cantos nos diluimos", cuya comisaría estaría a cargo de María Montero, para la Sala de Arte Joven de la Comunidad de Madrid". La propuesta "En los cantos nos diluimos" reunía a cinco mujeres jóvenes que se encontraban trabajando en los límites de sus disciplinas.

Con un presupuesto de tres mil euros, la instalación de Mallo buscaba generar ecosistemas diversos que ayudaran a diluir las barreras entre lo orgánico y lo inorgánico, entre lo natural y lo artificial, entre lo tecnológico y lo artesanal, entre lo macro y lo micro. Conceptualmente, se trataba de una instalación con cualidades responsivas, sensible, adaptable y en cambio constante. Un espacio vivo que reflejara nuestra propia complejidad, reaccionando a los comportamientos de quienes habitaban su interior (2017).

Para esto, Mallo ideó una membrana continua semipermeable capaz de generar un espacio interior, una superficie con la suficiente resistencia mecánica como para expandirse y contraerse de acuerdo con las acciones de sus ocupantes -Imagen 3-. Inicialmente, el proyecto comenzó con el desarrollo conceptual de la membrana: utilizando diferentes algoritmos y plataformas digitales de diseño, idearon una plataforma continua y orgánica que permitiera desplegarse y abatirse mediante una superficie triangular de elementos. A continuación, comenzaría la búsqueda del material idóneo para desarrollar una membrana responsiva que cumpliera las características necesarias para el proyecto. Luego de diferentes experimentaciones optaron por generar una membrana con látex líquido, aplicado de manera artesanal, para producir una superficie irregular que reprodujera el mundo natural, una piel continua, especializada en determinadas zonas ${ }^{5}$.

Con el fin de soportar la membrana, Mallo había diseñado una estructura externa rígida de piezas lobuladas de ratán, dobladas mediante un tratamiento con calor y humedad: parte de esta estructura híbrida se anclaba con tensores a las paredes y al techo de la sala, con el fin de dar estabilidad a la composición. Posteriormente, la membrana sería colgada a esta estructura externa mediante cordones de goma y ventosas de látex. Finalmente, el proyecto se completaba con la incorporación de cinco servomotores, diferentes sensores y un sistema de iluminación de noventa ledes distribuidos en nueve líneas, que otorgaban la interactividad a la instalación. Por desgracia, una serie de problemas técnicos impidieron su correcto funcionamiento.

4 El pabellón fue desarrollado entre enero y junio de 2017, siendo su inauguración el catorce de junio de ese mismo año, y manteniéndose abierto hasta el veintitrés de julio.

5 Para producir la membrana fue necesario elaborar un molde de 2,6 x 1,8 m, construido con madera DM de $3 \mathrm{~mm}$ cuyas partes fueron cortadas mediante laser. 
De forma adicional, y con el fin de reemplazar el efecto de espacio vivo y reactivo que generarían los motores, Mallo había optado por proyectar una serie de imágenes en movimiento sobre la membrana, imágenes que eran acompañadas por una narración de Cristina Peregrina "en torno al manejo de las emociones, las plantas y cristalizaciones en continuo crecimiento y la interacción de los habitantes que se animaban a tocar la superficie, desencadenando movimientos aleatorios" (Mallo, 2017). Por último, el prototipo se completaba con Caín, una performance experimental de la Asociación de Teatro ETSAM, que registraba las relaciones corporales entre los habitantes y la envolvente.

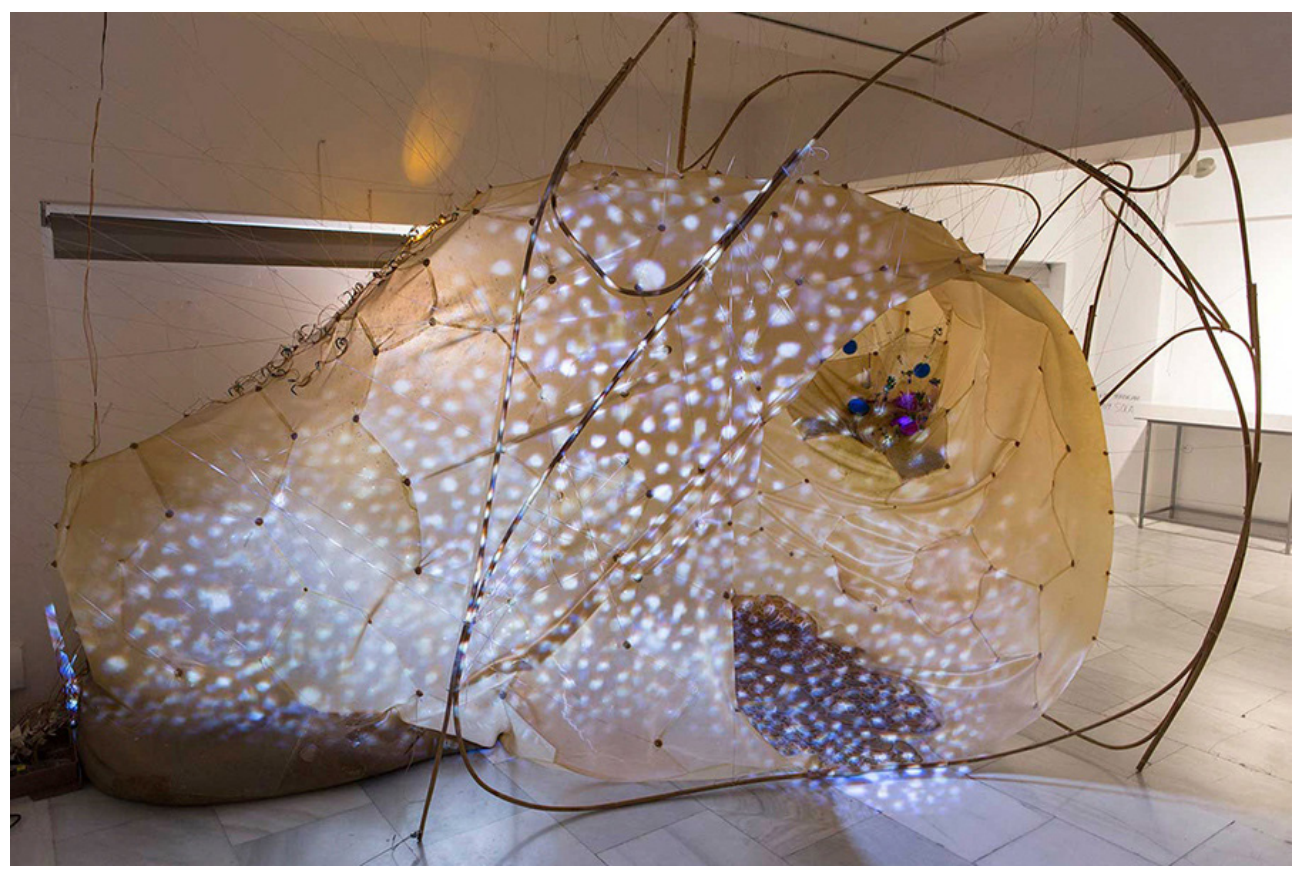

Imagen 3. Ecosistemas emocionales diversos. Diseñada dentro de una plataforma digital, se trata de una membrana continua y orgánica con capacidad para desplegarse y abatirse sobre sí misma. [Fuente: https://mariamallo.com/Ecosistemas-Emocionales-Diversos]

Como acabamos de ver, María Mallo también utiliza el vídeo como parte constitutiva de sus obras: piezas audiovisuales que otorgan una variable temporal, un proceso dinámico que marca el paso del tiempo a la vez que desdibuja y cualifica los límites físicos. En la obra, el vídeo ocupa la función de una variable intrínseca de cambio, un sistema de producción dinámica que potencia las posibilidades del espacio en interacción con los usuarios. Un ejemplo interesante al respecto fue el proyecto Breeding Space. Un proyecto producido para la Biennale de Rabat 20196,

$6 \quad$ La $1^{\text {a }}$ Bienal de Arte y Arquitectura de Rabat, realizada entre el veinticuatro de septiembre y el dieciocho de diciembre del 2019, fue comisariada por Abdelkader Damani -director del Frac Centre de Orleans-. La Bienal se llevó a cabo en diferentes lugares de la ciudad, y tenía por objetivo reunir solo a mujeres para que expusieran: sesenta y cuatro artistas de treinta países, donde se reunieron diferentes disciplinas que incluían las artes plásticas, el teatro, el cine, la coreografía y la literatura. 
cuya temática proponía "repensar el origen del mundo". Conceptualmente, se trataba de mirar al pasado a través del uso de la tecnología, una herramienta utilizada para acercarse a la naturaleza, "... una obra ligada a las estaciones, viva, que crece, que se cultiva y que incluso genera subproductos comestibles" (Mallo, 2020). Se trataba de una videoinstalación de 3,7 $\mathrm{m}$ de diámetro y 2,5 $\mathrm{m}$ de alto, diseñada mediante un algoritmo generativo digital y después materializada mediante la utilización de micelio de seta de ostra sobre paja.

A través de una serie de vídeos, es posible reconstruir el proceso que la autora siguió para su diseño y construcción: utilizando para esto un algoritmo digital, Mallo desarrollaría una nube de puntos alrededor de un núcleo base, para después generar una malla espacial compleja, una estructura triangular reparametrizada mediante un mallado dinámico que, a continuación, se convertiría en una malla de hexágonos irregulares alabeados que reproducían patrones semejantes a los existentes en la naturaleza -Imagen 4-

Posteriormente, María Mallo seleccionaba las opciones y variables que se aproximaban a los requerimientos espaciales previamente definidos: una morfología alterada para producir un cobijo con diferentes gradientes de opacidad y un lado abierto. Un espacio materializado a través de un endoesqueleto de varillas de hierro soldadas de $1 \mathrm{~cm}$ de diámetro, un encofrado perdido de tableros de madera DM de $2 \mathrm{~mm}$ cortada en láser y un suelo blando compuesto por telas tradicionales marroquíes rellenas. Completaba la composición una pieza audiovisual: Amplifying del grupo Espírituescalera", en donde narraba "otros mundos posibles" (Mallo, 2020); una composición audiovisual que se unía al espacio, lo completaba, lo alteraba, lo dinamizaba, lo trastocaba.

El vídeo, proyectado en el interior de este complejo espacio, se fragmentaba, descomponiéndose entre los diferentes planos inclinados que conformaban el interior del habitáculo. El registro rompía los límites: crece, se altera y fluctúa. Un efecto tridimensional fantástico que perturba y resignifica lo físico en un bucle constante e irreal. Se trata de un espacio que mezcla sonidos, imágenes y formas, en una relación compleja en donde se produce un intercambio entre personas y formas ${ }^{8}$.

\footnotetext{
Espírituescalera es un colectivo cinematográfico audiovisual creado en Madrid en el invierno de 2014 por Antonio Llames, Lucas Torralbo y Alejandro Pérez Castellano. Una mezcla entre artistas, investigadores y programadores que buscan explorar las diferentes posibilidades de lo cinematográfico, de las imágenes y del sonido en movimiento, una búsqueda por romper las clásicas fronteras, para crear obras materiales desde el presente pero que tengan una comunicación con el futuro. En Amplifyng, los autores desarrollan una compleja e impactante pieza audiovisual en donde, acompañado por una música con un fuerte ritmo creciente, el espectador se sumerge en un escenario vertiginoso, biológicamente cambiante, en donde se suceden una serie de fragmentos de imágenes que se superponen con rastros de residuos electrónicos, envases, fluidos en movimiento y en ebullición, manos, ojos y pieles y superficies plegadas: "En lo que se descompone hay un rastro que se mitiga, y permanece. En el detalle hay un territorio, y un conflicto" (espírituescalera, 2019).

8 En enero de 2020, el proyecto Breeding Space, fue donado al Museo Mahamed VI de Rabat. De forma complementaria, Mallo produjo una maqueta Breeding Space Model; está fue adquirida en julio de 2020 por el Museo Frac Centre-Val de Loire de Orleans, Francia. Sin embargo, el museo decidió reemplazar el micelio por una impresión 3D de PLA termocrónico de color blanco, debido a que el micelio resultaba complejo de mantener.
} 


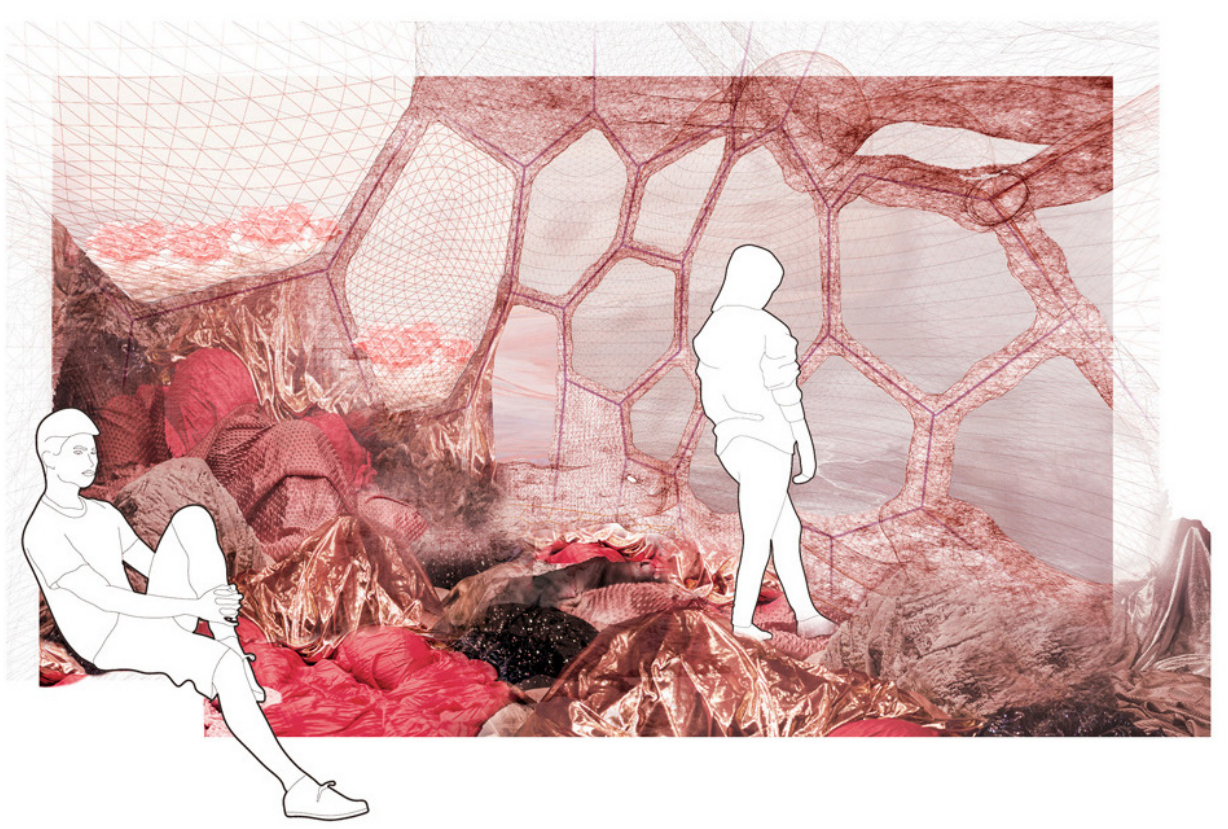

Imagen 4. Breeding Space. El vídeo, proyectado en el interior de este complejo espacio, se fragmentaba, descomponiéndose entre los diferentes planos inclinados que conformaban el interior del habitáculo. [Fuente: https://mariamallo.com/Breeding-Space]

\section{La temporalidad de la obra de arte: el carácter de lo efímero}

De acuerdo con su raíz griega, el vocablo efímero significa 'que dura un solo día'; por analogía también quiere decir, 'de brevísima duración', pero conlleva "lo inevitable, lo demarcado dentro de los infranqueables límites cronológicos" (Zátonyi, 2011c:127). Y es aquí precisamente en donde entra en juego uno de los elementos más importantes en la obra de Mallo: el tiempo. Mallo registra el tiempo en sus obras, inventariando su carácter efímero y fenomenológico, así como la interacción de sus creaciones con los individuos y su entorno. Se trata de un registro de lo que ya fue, de lo que estuvo, y sin embargo ya no existe.

En esencia, Mallo transita un camino de lo analógico a lo digital, de lo abstracto a la singularidad, un ida y vuelta que en el proceso crece y se enriquece, provocando de forma mediata o inmediata una serie de transformaciones en el todo, cuyo valor estará determinado por la densidad, calidad y cantidad de estos cambios.

Utilizando tecnología digital, sensores y servomecanismos, Mallo crea formas topológicas que, al igual que un organismo vivo, crecen, se mueven, fluctúan y por último se extinguen. En el proceso, el usuario actúa como cronista de esta percepción sensorial: son construcciones espaciotemporales donde establece una obra sensible a los cambios, donde el espectador es libre de seguir una multiplicidad de caminos, su esencia parece ser la variedad, la dinámica de las opciones múltiples. Una secuencia de perspectivas espaciales que actúan como 
detonadores de una serie de recuerdos que se unifican y amalgaman en el espacio para construir y reconstruir significados. Un momento cargado de imágenes, luces, sonidos y formas, que contribuyen a generar una atmósfera compleja, ambigua, multifocal y hasta a veces oscura también.

Un ejemplo interesante al respecto es el vídeo Cascarones y Cuerpos $^{9}$ del proyecto con el mismo nombre, una performance interpretada por tres artistas: dos de ellos, María Ruiz Villar y Lucía Redondo Rubio, danzaban utilizando una escultura portable, la Nasselaria XL, mientras que un tercer artista, Alejandro García Muñoz, narraba diferentes fragmentos ${ }^{10}$ del libro 58 indicios sobre el cuerpo de Jean-Luc Nancy. En el vídeo, se observa como los artistas transportan una escultura, producida a partir de una chapa de latón de $1 \mathrm{~mm}$ de espesor, cortada a láser, con incisiones, lijado, pulido y doblado manual. El vídeo, grabado y producido por la misma Mallo, buscaba "transmitir algo de lo mágico que allí ocurrió" (Mallo, 2019). En otras palabras: "...la diferencia entre ver una pieza colgada y verla entrelazada entre cuerpos, es igual que la diferencia entre ver un insecto disecado o verlo en movimiento. Es una cuestión sobre lo vivo y lo muerto" (Mallo, 2019).
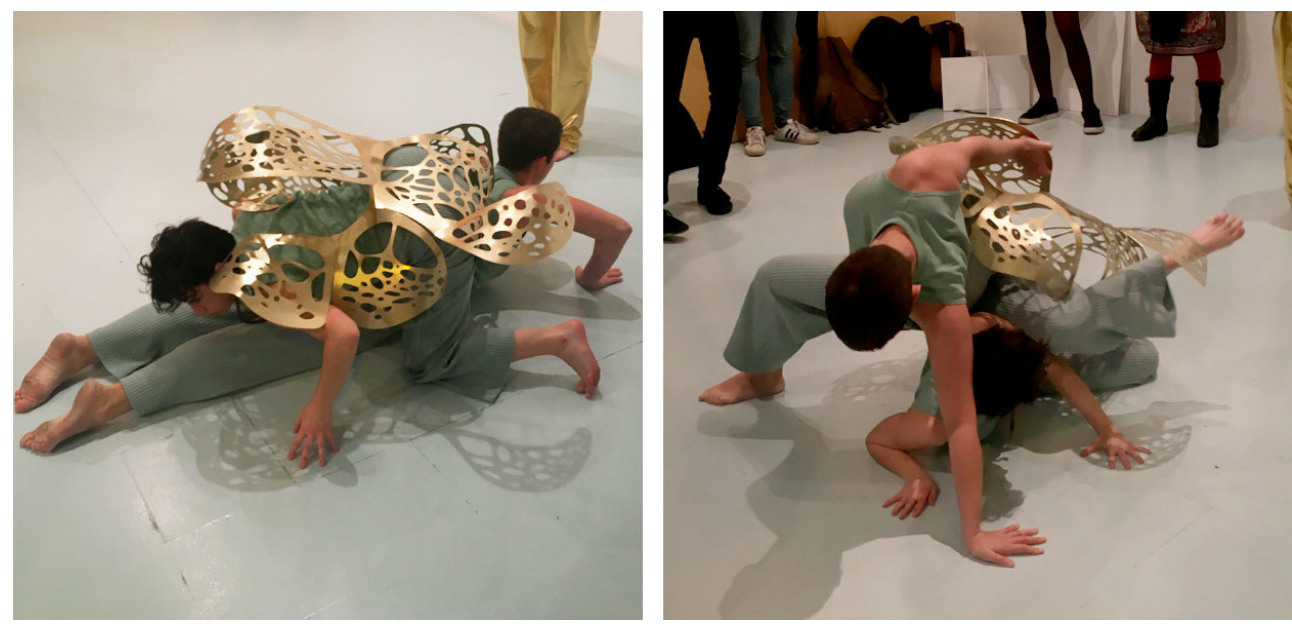

Imagen 5. Cascarones y Cuerpos. Un proceso donde los artistas transportan una escultura, generada a partir de una chapa de latón de $1 \mathrm{~mm}$ de espesor, cortada a láser, con incisiones, lijado, pulido y doblado manual. [Fuente: https://Maríamallo.com/Cascarones-y-Cuerpos]

Otro proyecto relacionado con el concepto de lo efímero fue Ludantia, desarrollado en 2018. María Mallo había sido invitada por los organizadores de la $1^{\text {a }}$ Bienal Internacional de Educación en Arquitectura para la infancia y la juventud, para que desarrollara una serie de formas naturales con la que los niños participantes pudieran jugar durante la Bienal, que se celebraría en el Pazo da Cultura de Pontevedra, Galicia.

\footnotetext{
9 Subvencionada por el Área de Gobierno de Cultura y Deportes del Ayuntamiento de Madrid, el proyecto formaba parte de una perfomance desarrollada el 15 de marzo de 2019, como parte del programa OFF de Madrid Design Festival y del programa VIP de ARCO https:/Maríamallo.com/Cascarones-y-Cuerpos

1023 fragmentos: $1,2,3,4,5,12,17,18,22,24,27,28,29,30,34,35,36,38,42,45,47,52,54$.
} 
Con el fin de facilitar su producción, a la vez que otorgaba calidez al producto, optaron por piezas fabricadas en madera de contrachapado cortadas mediante una fresadora CNC y los cantos redondeados mediante fresadora de mano. Para la exposición, los elementos se dispusieron colgados en el interior de una inmensa caja de madera -Imagen 6-, donde los niños iban extrayendo una serie de formas orgánicas planas de diferentes tamaños para después, utilizando una serie de bridas plásticas, poder combinarlas para crear formas y espacios tridimensionales temporales de forma irregular: espacios lúdicos de experimentación, “... formas orgánicas desconocidas que recuerdan a fantásticos universos submarinos o extraterrestres" (Mallo, 2019). Un espacio donde “... la ingravidez, los umbrales, las transparencias y las sombras nos invitaban a entrar y salir, encontrar refugios, manipular, construir y dibujar dejando volar libre la imaginación" (Mallo, 2019).
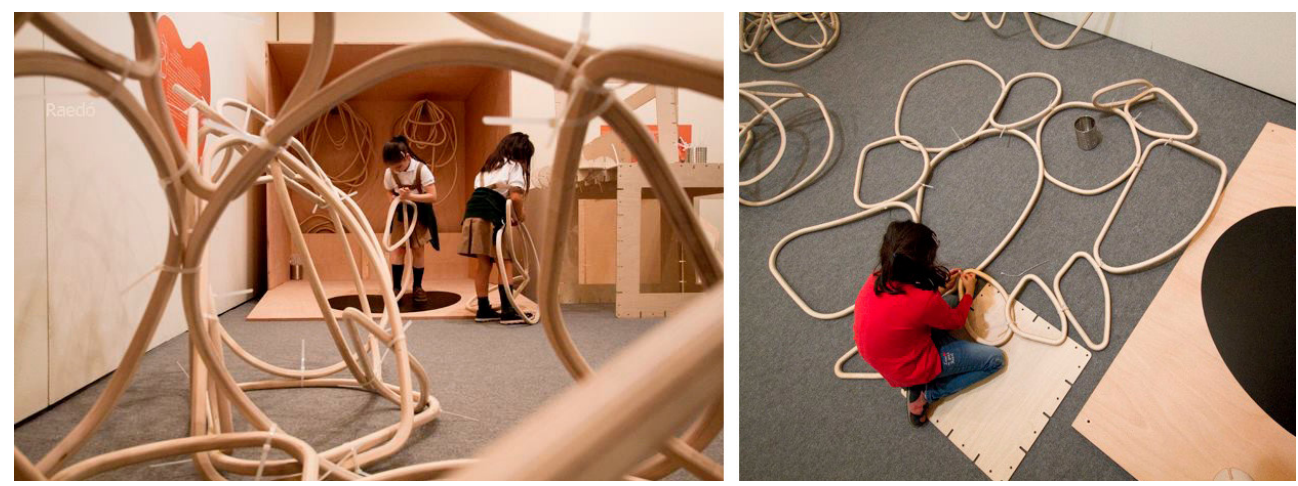

Imagen 6. Ludantia. Una inmensa caja de madera, donde los niños iban extrayendo una serie de formas orgánicas para después combinarlas y crear formas y espacios tridimensionales temporales de forma irregular. [Fuente: https://mariamallo.com/Ludantia]

\section{Conclusiones: un manifiesto en fragmentos}

De acuerdo con el diccionario de la Real Academia Española, la palabra manifiesto deriva del latín manifestus, y se refiere al 'escrito en que se hace pública declaración de doctrinas, propósitos o programas' (RAE, 2020). En esencia, se trata de un material documental, no necesariamente escrito, a través del cual se da a conocer una idea o forma de pensar sobre un tema determinado. Para los escritores Mangone y Warley (1994), los manifiestos buscan instaurar una serie de aspectos 'novedosos' sobre un contenido concreto, su carácter polémico se inserta en el presente, algo que, para Claude Abastado (1980), "se mueve entre la ruptura y la refundación, entre la denuncia y la afirmación" (3-11). En el caso específico del arte, los manifiestos fueron utilizados por las vanguardias, como una expresión que simbolizaba una declaración de principios sobre la voluntad de los estilos de un nuevo movimiento; su importancia comienza a tomar fuerza a finales del siglo XIX, para consolidarse durante el siglo $\mathrm{xx}$ con nuevos medios y plataformas de difusión.

Con la llegada de la tecnología digital, el concepto de manifiesto adquiriría un nuevo significado, cuando un grupo de artistas disruptores comenzarían a usar estos nuevos espacios y sistemas virtuales no solo para producir sus obras, sino también como 
un medio para transmitir sus mensajes al público estableciendo una nueva relación con ellos: una sobremultiplicación de su alcance, un vínculo que trasciende al tiempo y al espacio.

En el caso de María Mallo, al analizar sus obras a través de su producción audiovisual, es posible descubrir cómo estas exteriorizan sus emociones, nos cuentan historias, plantean preguntas y comparten sus pensamientos con sus seguidores. Utilizando un lenguaje enriquecido donde la obra simula, Mallo imagina y crea infinitos lugares diferentes: un mensaje comunicado en el tiempo, un mensaje que construye historias y se funde con estas, para transformarse en una herramienta material visible y operativa, que ocupa un lugar y un tiempo específico en que se hace. Y si bien el arte no está subordinado al medio, se trata de un mecanismo digital, a través del cual Mallo elabora un metalenguaje que posteriormente utiliza para transmitir su mirada del mundo.

Bajo una nueva sensibilidad moldeada por la tecnología, utiliza el vídeo para comunicar e intercambiar contenido, conectando a través de la red. Este transvasar nos inquieta, nos espanta, parece querer provocar una ruptura en el discurso teórico. Una búsqueda que la ha llevado a soltar la imaginación, escudriñando la libertad hacia lo imposible, en busca de lo utópico. Una búsqueda por la generación de formas teseladas irregulares eficientes, capaces de adaptarse al entorno y mejorar su respuesta frente a las acciones de la gravedad. Un proceso investigativo que, gracias al desarrollo de la tecnología de diseño paramétrico y de prefabricación digital junto con la experimentación con diferentes materiales, pudo desarrollar un mayor acercamiento a la complejidad de los patrones naturales, para generar una nueva familia de formas que no imitan a la abstracción de la geometría; su crecimiento y evolución queda emparentada con el medioambiente.

En su esencia, la obra de Mallo presenta el carácter de manifiesto, pero un manifiesto fragmentado: son recortes dispersos que deben ser encajados para revelar la obra al completo; una obra abierta donde el espectador deberá descifrar el código de lectura que le da sentido y competencia a la obra. Se trata de un proceso multidireccional y profundamente hipertextual. Y es precisamente allí en donde se encuentra su valor: sus obras pueden ser entendidas como una sucesión de layers, un fenómeno complejo que, a través de una sucesión de capas, muta y oculta detalles en un bucle continuo de renovación, para que, una vez superpuestos, establezcan un mensaje complejo, multifocal, pero sobre todo abundante en contenido.

En los últimos tiempos, María Mallo ha establecido una comunidad de trabajo en red, en donde desarrolla un proceso creativo de intercambio. Un trabajo donde las emociones y una sinergia elaboran una creación colectiva. Se trata de un proceso dinámico, algo semejante a un sistema neuronal, arbóreo; una estructura jerárquica, generadora y productora de contenidos, pero a la vez llena de enigmas y de misterios.

\section{Bibliografía}

Abastado, C. (1980). "Introduction à l'analyse des manifestes”. Littérature, núm. 39, 3-11. Espirituescalera. (2019). “Amplifyng”. Recuperado de https://espirituescalera.es/proyectos/ amplifyng-bienal-femenina-de-rabat-2019 (Fecha de acceso: 15/11/2021).

Mallo, M. (2017). “Ecosistemas Emocionales Diversos”. Recuperado de: https://mariamallo. com/Ecosistemas-Emocionales-Diversos (Fecha de acceso: 15/11/2021). 
Mallo, M. (2017). "Symposium Towards the Frontiers of Arch". Recuperado de https:// mariamallo.com/Symposium-Towards-the-Frontiers-of-Arch (Fecha de acceso: 15/11/2021).

Mallo, M. (2018). "Ludantia". Recuperado de https://mariamallo.com/Ludantia (Fecha de acceso: 15/11/2021).

Mallo, M. (2018). "Ludantia". Recuperado de https://ludantia.wixsite.com/bienalinternacional/i-bienal-internacional (Fecha de acceso: 15/11/2021).

Mallo, M. (2018). "Ludantia". Recuperado de https://www.asociacionludantia.org/archivo/ (Fecha de acceso: 15/11/2021).

Mallo, M. (2019). "Breeding Space". Recuperado de https://mariamallo.com/BreedingSpace (Fecha de acceso: 15/11/2021).

Mallo, M. (2019). "Cascarones y Cuerpos". Recuperado de https://mariamallo.com/ Cascarones-y-Cuerpos (Fecha de acceso: 15/11/2021).

Mallo, M. (2020). Comunicación personal. 26 de marzo de 2021.

Mallo, M. (2021). “PII-01”. Recuperado de https://mariamallo.com/PII-01 (Fecha de acceso: $15 / 11 / 2021)$.

Mangone, C. \& Warley, J. (1994). El manifiesto. Un género entre el arte y la política. Buenos Aires: Biblos.

Zátonyi, M. (2011a). Arte y creación. Los caminos de la estética. Buenos Aires: Capital Intelectual.

Zátonyi, M. (2011b). Juglares y Trovadores: derivas estéticas. Buenos Aires: Capital Intelectual.

Zátonyi, M. (2011c). Arquitectura y Diseño. Análisis y teoría. Buenos Aires: Nobuko. 